\title{
Influence of the Pre-Treatments and Process Temperature on the Adhesion of TiN Films Deposited by PBII\&D Over Nitrided Austenitic Stainless Steel
}

Laura Silvia Vaca ${ }^{a *}$, Juan Pablo Quintana ${ }^{b}$, María Agustina Guitar $^{c}$, Daniel Vegad, Sonia Patricia Brühl ${ }^{a}$,

\author{
Adriana Márquez $z^{b}$
}

\author{
${ }^{a}$ Grupo de Ingeniería de Superficies, Universidad Tecnológica Nacional - UTN, Facultad Regional \\ Concepción del Uruguay - FRCU, Entre Ríos, Argentina \\ ${ }^{b}$ Instituto de Física del Plasma - INFIP, Consejo Nacional de Investigaciones Cientificas y Técnicas - \\ CONICET, Universidad de Buenos Aires - UBA, Buenos Aires, Argentina \\ ${ }^{c}$ Functional Materials, Materials Science Department, Saarland University, Saarbrücken D-66123, Germany \\ ${ }^{d}$ Departamento Física de la Materia Condensada, Gerencia Investigación y Aplicaciones - GIyA, \\ Comisión Nacional de Energía Atómica - CNEA, San Martín, Buenos Aires, Argentina
}

Received: April 05, 2019; Revised: July 05, 2019; Accepted: August 15, 2019

In this work the influence of pre-treatment cleaning processes in the adhesion of TiN films deposited by the plasma based ion implantation and deposition (PBII\&D) process over plasma nitrided AISI 316L stainless steel was investigated, varying the gas composition, the duration of the sputtering process and the temperature in the same deposition chamber. The TiN film morphology was scrutinized with scanning electron microscopy on the surface complemented with focus ion beam for the cross section. The film microstructure was characterized with $\mathrm{X}$ ray diffraction. The adhesion of the coatings was studied using the Scratch Test with constant load at different values and the Rockwell C indentation method as well. It was found that only with the sputtering carried out in a $\mathrm{H}_{2}-\mathrm{Ar}$ gas mixing at $300^{\circ} \mathrm{C}$ temperature used as pre-treatment was successful to prepare the nitrided surface for the subsequent TiN deposition by the PBII\&D process.

Keywords: PBII\&D, TiN films, duplex treatment, adhesion.

\section{Introduction}

The AISI 316L austenitic stainless steel is widely used in the chemical, food, petrol and in nuclear industries as well as in biomaterial technology due to the excellent corrosion resistance in aggressive environments and good biocompatibility ${ }^{1}$. However, its low hardness, high friction coefficient and poor wear resistance limit potential applications ${ }^{2}$. To improve their tribological properties without losing corrosion resistance, several surface treatments have been applied and positives results were obtained with plasma assisted processes ${ }^{3}$. It is known that the "S" phase or expanded austenite produced after ion nitriding increases hardness and wear resistance in stainless steels, but the corrosion resistance is not always maintained ${ }^{4,5}$.

Ceramic coatings have been investigated to improve not also wear but corrosion resistance of steels, due to their chemical inertness in aggressive environments. Coatings like TiC, TiN and WC have a high hardness and are commonly used for hardening cutting tools made of high speed steel. Many of these coatings, e.g. TiN, can be applied by plasma vapor deposition process (PVD). Cathodic arc deposition is a useful PVD technique for the growth of films that promotes dense nanostructured films formation with good adhesion and high deposition rate ${ }^{6}$.
Plasma Based Ion Implantation and Deposition (PBII\&D) is a technique in which the sample to be treated is biased at high pulsed voltage. A metal plasma source is normally used to generate the condensable plasma, the metallic ions are implanted during the pulse time on, and they condense at the surface in the time off. The high ion energy, of some keV, generates a mixing layer at the interface in the beginning, and cause the penetration of the ions a few atomic layers in the growing film, leading to an atomic rearrangement in favor to the densification of the film ${ }^{7,8}$.

The adhesion of the coatings to the substrate is a fundamental factor in all the applications to prolong the lifetime of workpieces. Several studies have demonstrated that duplex processes, so as PVD hard coatings deposited onto ion nitrided stainless steel improved the adhesion and wear resistance because the nitrided substrate acts as mechanical support for the hard coating, avoiding a plastic deformation that could cause the coating failure due to the high hardness gradients ${ }^{9-13}$. It is well known that the presence of oxide layers and contaminants on the stainless steels are also present after ion nitriding and the removing of them is a problem necessary to solve before the coating process. The most common techniques to improve films adhesion are the pre-treatments for surface cleaning before introducing the samples in the reactor, as well as the deposition of a metallic interlayer between the substrate and the film ${ }^{14,15}$. 
Barshilia et al. observed that the incorporation of a thin Ti interlayer helps in dissolving oxide contaminants at the interface ${ }^{16}$. A study about the influence of surface grinding and plasma nitriding on residual stresses for TiAlN and Ti/ TiAlN coating deposited onto X37CrMoV5-1 steel, found the film adhesion improved when the substrate was plasma nitrided. The higher hardness of the nitrided samples was related to an increase of compressive residual stresses of the substrate, the slight difference between the residual stresses of the substrate before deposition and the residual stress of the coating benefited the film adhesion ${ }^{11}$.

In some studies of coatings over stainless steels, Ar sputtering has been applied to clean the samples once they were in the reactor to remove the characteristic passive oxide layer of this kind of steel ${ }^{17}$. A few works included $\mathrm{Ar}-\mathrm{H}_{2}$ to clean the surface before coating stainless steels or mild steels ${ }^{16,19}$, while $\mathrm{Ar}-\mathrm{H}_{2}$ or $\mathrm{H}_{2}$ sputtering has been applied with very good results to clean the stainless steels before plasma nitriding treatment ${ }^{18,20}$. $\mathrm{Ar}-\mathrm{Kr}$ sputtering at $600{ }^{\circ} \mathrm{C}$ was employed as a cleaning treatment of nitrided tool steels before coating with $\mathrm{AlTiN}^{21}$.

There are also several studies about the benefits achieved with the deposition of thin $\mathrm{Ti}$ interlayer, as the inhibition of crack propagations and the reduction of surface residual stresses, among others, that improve the coating/substrate adhesion $^{11,22,23}$. In a previous work, it was found that a $\mathrm{Ti}$ interlayer deposited onto the $316 \mathrm{~L}$ improved the adhesion of PBII\&D TiN coatings ${ }^{24}$.

However, a scarce number of publications dealt with hard coatings on plasma nitriding austenitic stainless steels and the effect of the nitrided layer and the pre-cleaning treatment of these modified surfaces on the adhesion of hard coatings deposited with PVD. This work presents the results of the influence of pre-cleaning processes on the adhesion of Ti/TiN films deposited by PBII\&D over AISI 316L which were previously plasma nitrided. The studied variables of the cleaning treatment after Plasma Nitriding (from now on PN) and before the PBII\&D processes included the sputtering gas composition and the temperature.

\section{Material and Methods}

Samples of $5 \mathrm{~mm}$ high and $25 \mathrm{~mm}$ in diameter were cut from an AISI 316L bar whose chemical composition, certified by the manufacturer, is presented in Table 1 . They were rectified in one face. The surface to be treated was grinded with increasing grade up to $1000 \#$ grid $\mathrm{SiC}$ paper.
The PN process was carried out in an industrial device of IONAR S.A. (Argentina). The samples have been sputtered for 2.5 hours, at $450{ }^{\circ} \mathrm{C}$ of temperature, in a gas mixture of $50 \% \mathrm{Ar}$ $+50 \% \mathrm{H}_{2}$ and then plasma nitrided in the same reactor for 20 hours, at $420{ }^{\circ} \mathrm{C}$ temperature, with a DC pulsed discharge, in a gas mixture of $20 \% \mathrm{~N}_{2}+80 \% \mathrm{H}_{2}$. After PN the samples have been grinded with $1000 \#$ grid $\mathrm{SiC}$ for 1 minute. The nitrided layer consisted, as it was already published ${ }^{25}$, of expanded austenite, 9-10 microns width, and with approximately 950 HV hardness. Before the coating process, all nitrided samples were cleaned using acetone for 30 minutes in an ultrasonic bath, and after that, they were introduced into the experimental cathodic arc equipment, which scheme is presented in Fig. 1. The electrical circuit of the discharge is powered by a current source of 18 $\mathrm{kW}$. The arc discharge takes place between an electrode system consisting of a titanium cathode and the stainless steel vacuum chamber that acts as anode; both electrodes are cooled by water. The vacuum system consists of two diffuser pumps assisted by a mechanical pump. The base pressure of the chamber is $1.10^{-3} \mathrm{~Pa}$. The device allows the control of gas flow of Ar, $\mathrm{H}_{2}$ and $\mathrm{N}_{2}$ employing mass flow controllers. The sample holder faces the cathode and has a heater, which allows heating up the sample to $300^{\circ} \mathrm{C}$. The sample holder is biased with a high voltage pulse generator of $12 \mathrm{~kW}(0-15 \mathrm{kV}$, pulse width $50 \mu \mathrm{s}, 20$ A maximum current, variable frequency from 100 to $700 \mathrm{~Hz}$ ). The nitrided samples were placed at $0.25 \mathrm{~m}$ away from the cathode surface in the PVD chamber.

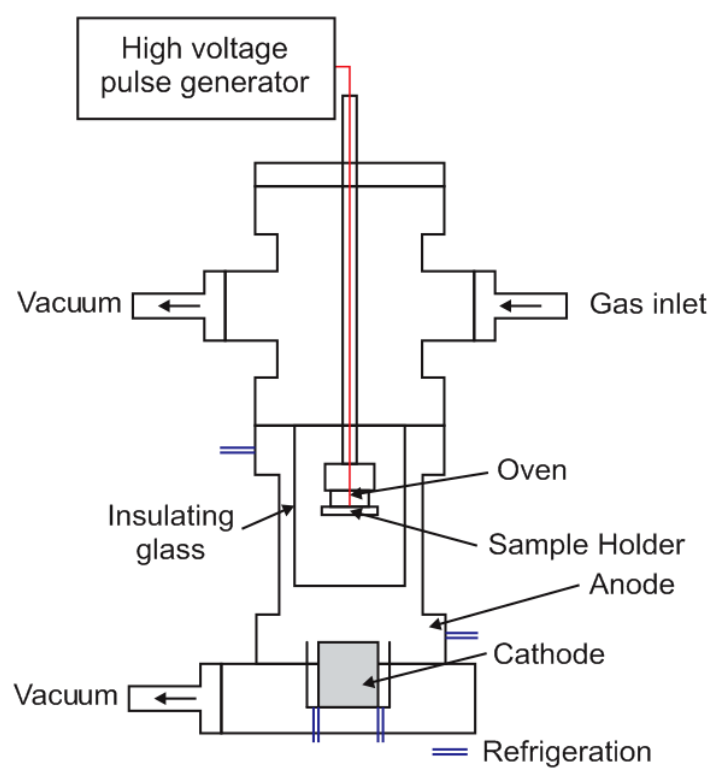

Figure 1. Scheme experimental Cathodic Arc equipment.

Table 1. Chemical composition AISI 316L

\begin{tabular}{ccccccccccc}
\hline $\mathrm{C}$ & $\mathrm{Si}$ & $\mathrm{Mn}$ & $\mathrm{P}$ & $\mathrm{S}$ & $\mathrm{Co}$ & $\mathrm{Cr}$ & $\mathrm{Mo}$ & $\mathrm{Ni}$ & $\mathrm{Cu}$ & $\mathrm{N}$ \\
\hline 0.017 & 0.33 & 1.44 & 0.037 & 0.030 & 0.09 & 16.25 & 2.03 & 10.07 & 0.24 & 0.053 \\
\hline
\end{tabular}


The surfaces were pre-treated with sputtering in a glow discharge at $10 \mathrm{~mA}$ current and a pressure of $40 \mathrm{~Pa}$. The arc current for the PBII\&D process was set at $100 \mathrm{~A}$. The Ti interlayer was deposited at the base pressure, while the TiN films were obtained in a $\mathrm{N}_{2}$ atmosphere at $10^{-2} \mathrm{~Pa}$. The samples were biased with negative pulses of $6 \mathrm{kV}$ peak voltage, at frequency of $200 \mathrm{~Hz}$. All the samples were coated with Ti/ TiN films $(1.9 \pm 0.2) \mu \mathrm{m}$ thick.

Five process conditions were carried out and the main parameters of each one are listed in Table 2. In this table, the sputtering parameters of the pre-treatment and the PVD process are described, including the condition denominations.

The samples of condition I were cleaned in Ar glow discharge for 60 minutes and the whole process was performed at room temperature. For the samples of condition II the whole process was carried out at $300^{\circ} \mathrm{C}$. For condition III the sputtering time was increased to 150 minutes. For the other two conditions (IV and V) the gas atmosphere was changed adding $\mathrm{H}_{2}$ to the mixture, and the time was set at $150 \mathrm{~min}$, keeping the samples at room temperature for condition IV and at $300{ }^{\circ} \mathrm{C}$ for condition $\mathrm{V}$.

The surface coating was observed with a Scanning Electron Microscope (SEM) Philip 515, and combining a Focused Ion Beam (FIB) with the SEM, the cross section structure was studied. The cross section features were also examined with SEM in samples cut in a cryogenic bath. The samples were discs of $1 \mathrm{~mm}$ high cut from the same stainless steel bar. Some of them were marked in half with a deep groove from the back face to the face to be treated. After that, they were nitrided in the same process as the thick discs, and coated with Ti/TiN. After removing them from the PVD device, they were immersed in liquid nitrogen and broken. X Ray Diffraction (XRD) in the Bragg-Brentano geometry using $\mathrm{Cu}-\mathrm{K} \alpha$ radiation was used to determine the crystal structure.

The coating adhesion was evaluated by two methods. One of them was the Scratch Test, employing a Scratch Tester designed and built according to ASTM C-1624 Standard ${ }^{26}$, with constant loads for each scratch but increasing it from 5 to $50 \mathrm{~N}$, under unlubricated conditions and at room temperature. The considered critical load was the load at which the film presented some delamination, inside or beside the track.
The advantage of proceeding with a constant load is that the indenter acts for a long way with the same speed and it is possible to analyze the damage throughout the track, making also possible to differentiate damage levels for each load. Besides, the fact of being able to perform the test several times with the same load leads to greater reliability due to the statistic. This test measures the adhesion strength between the film and the substrate system. From the track observation, it is possible to identify the type of failure, which depends on the film thickness, the substrate hardness and the interface adhesion, among others ${ }^{12}$. The second method, Rockwell C Indentation test was also carried out employing a Rockwell Indenter and the indentations were observed with an optical microscope to classify the adhesion according the criteria from H1 to H6 scale of VDI 3198 Standard, the chart is reproduced in Fig. $2^{27}$. This standard only suggests practicing, at least, two indentations in each sample in order to evaluate the damage, due to the slight variability of the test. Considering that the adhesion interphase could not be homogeneous all across the samples, several indentations were carried out in each one. In this test, compression forces are produced during the loading process and the shear forces increase toward the border of the track.

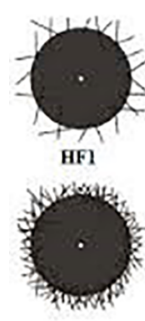

HF2

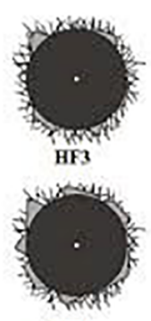

HF 4

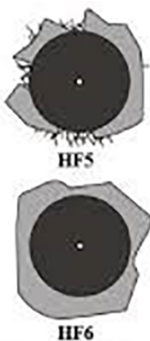

HF6

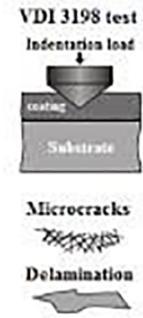

Figure 2. VDI 3198 test indentation evaluation.

\section{Results and Discussions}

The appearance of the samples when they were removed from the PVD chamber resulted different in each condition. For the first three conditions (I, II and III), when the sputtering gas was only argon, in more than $60 \%$ of the samples, the coating did not look homogeneous at all and, at least in 50\%

Table 2. Summary of the main parameters of the five studied conditions

\begin{tabular}{lcc}
\hline \multicolumn{1}{c}{ Pre - treatment } & PVD process & Condition \\
\hline 60 minutes Ar sputtering & & I \\
Room temperature & PBII\&D & II \\
60 minutes Ar sputtering & PBII\&D+T & III \\
$300^{\circ} \mathrm{C}$ & PBII\&D+T & IV \\
150 minutes Ar sputtering & & \\
$300^{\circ} \mathrm{C}$ & PBII\&D & $\mathrm{V}$ \\
150 minutes $50 \% \mathrm{Ar}+50 \% \mathrm{H} 2$ sputtering & & PBII\&D+T \\
Room temperature & & \\
150 minutes $50 \% \mathrm{Ar}+50 \% \mathrm{H} 2$ sputtering & & \\
$300^{\circ} \mathrm{C}$ & & \\
\hline
\end{tabular}


of them it detached completely after a few minutes outside the processing chamber. For the condition IV, with the $\mathrm{H}_{2}$ incorporation in the gas mixture, only $10 \%$ of the coatings delaminated. Finally, in the case of condition V, all the films were homogeneous and no delamination was observed. Typical images of the coating surfaces are presented in Fig. 3. The picture of Fig. 3a) corresponds to a coating completely detached, Fig. 3b) shows a not homogenous film, and Fig. $3 c)$ exhibits a homogenous film. For this study only the samples in which the remaining coated area was more than $50 \%$ of the whole surface were considered.

\section{Microstructure}

Regardless of the pre-treatment conditions, the film morphology, structure and thickness did not present major variations, only the adhesion and mechanical properties of the interface, exhibited changes. For this reason, XRD results and FIB-SEM are showed for one condition only.

The SEM examination of the coated surface revealed the formation of droplets, characteristic of the PVD vacuum arc deposition, as it can be observed in Fig. 4a). Fig. 4b) presents images obtained by FIB-SEM in a cross section of a film of $(2100 \pm 50) \mathrm{nm}$ thickness, representative for all conditions. In this figure, it is possible to distinguish the Ti interlayer and the TiN layer.

Fig. 4c) shows the picture obtained from the sample cut in the cryogenic bath, where a columnar structure and the compactness of the film can be noted. It is also possible to differentiate the Ti interlayer and the interface with the nitrided layer.
XRD patterns for phase identification and residual stress estimation were recorded in a $2 \theta$ range from $30^{\circ}$ to $80^{\circ}$ in a Bragg-Brentano geometry. In Figure 5, a typical pattern is presented. It shows the most important peaks of $\gamma_{N}$ (expanded austenite) corresponding to the AISI 316L nitrided layer ${ }^{28}$. On the other hand, all TiN peaks were identified and only the (100) peak of Ti corresponding to the interlayer was detected $^{29,30}$. The positions of all TiN peaks were observed at a less angle comparing with the reference pattern, this fact indicates the expansion of the lattice parameter.

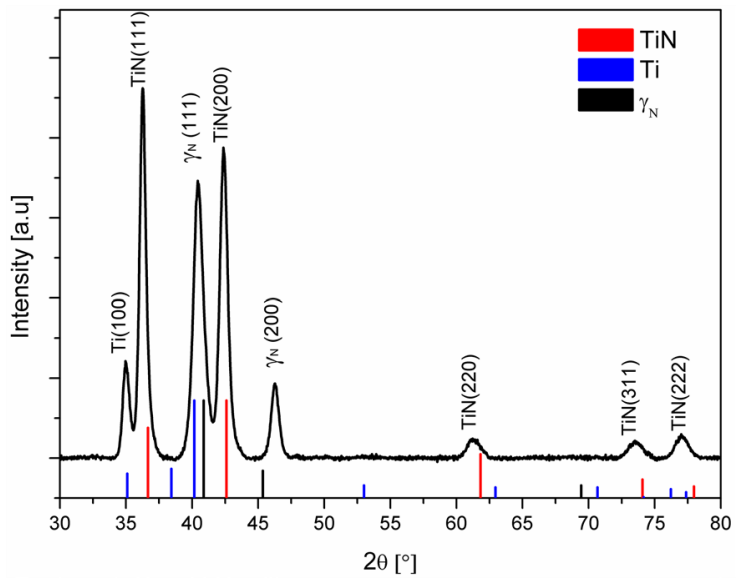

Figure 5. XRD Bragg-Brentano pattern of PBII\&D Ti-TiN coating.

Assuming an elastically isotropic solid with a rotationally symmetric biaxial stress state, compressive stress acting in the plane of the coating will give rise to an expansion of the
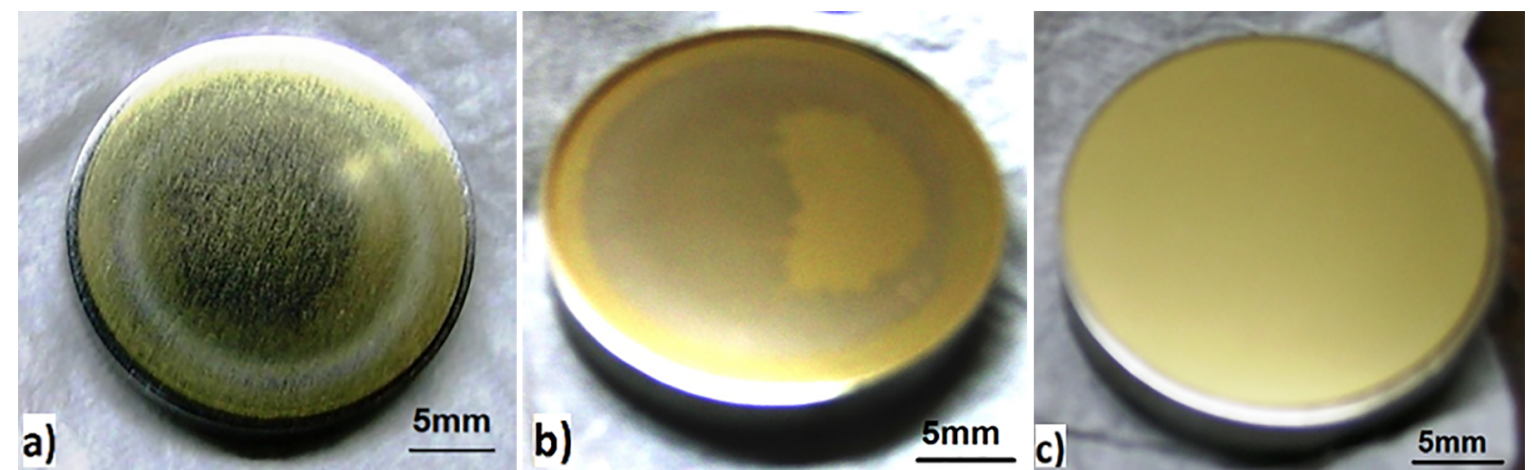

Figure 3. Typical images of the coating surfaces: a) coating completely detached, b) not homogenous coating, c) homogenous coating.
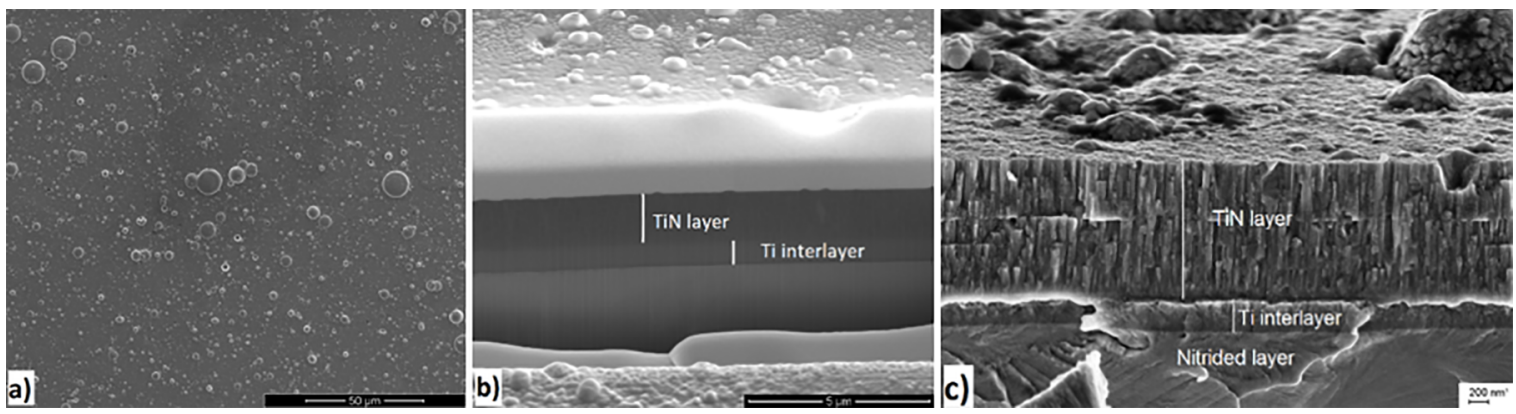

Figure 4. SEM image: a) surface film 650x, b) FIB-SEM thickness film: thick film10000x, c) columnar structure 50000x. 
planes parallel to the surface. In this simplified situation, the lattice parameter $\left(\mathrm{a}_{\mathrm{hk} \mid}\right)$ for a cubic lattice can be related to residual stress $(\sigma)$ as:

$$
a_{h k l}=a_{0}-\frac{2 v}{E} \sigma a_{0}
$$

where $a_{0}$ is the strain-free lattice parameter, $E$ is the Young's modulus and $v$ the Poisson's ratio. The residual stress was estimated by obtaining the lattice parameter from the (111) TiN peak position and taking the lattice parameter reported in the TiN reference card (ICDD card $\mathrm{N}^{\circ} 00-038-1420$ ) as $a_{0}$. For all the conditions, the estimated value was $\sigma \approx-9.1 \mathrm{GPa}$. Compressive residual stress is typical in coatings grown by cathodic arc ${ }^{31-33}$.

\section{Adhesion}

\subsection{Scratch test}

The same test was repeated in several samples, with the same load several times. Ten tests, at least, were performed for each condition.

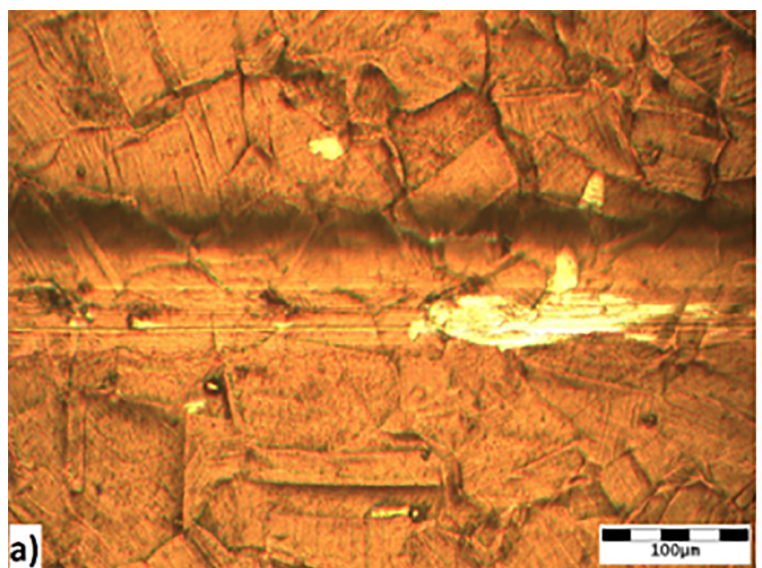

Figure 6. Scratch Test critical load 200x: a) Cond. I 20 N, b) Cond. II 5N.
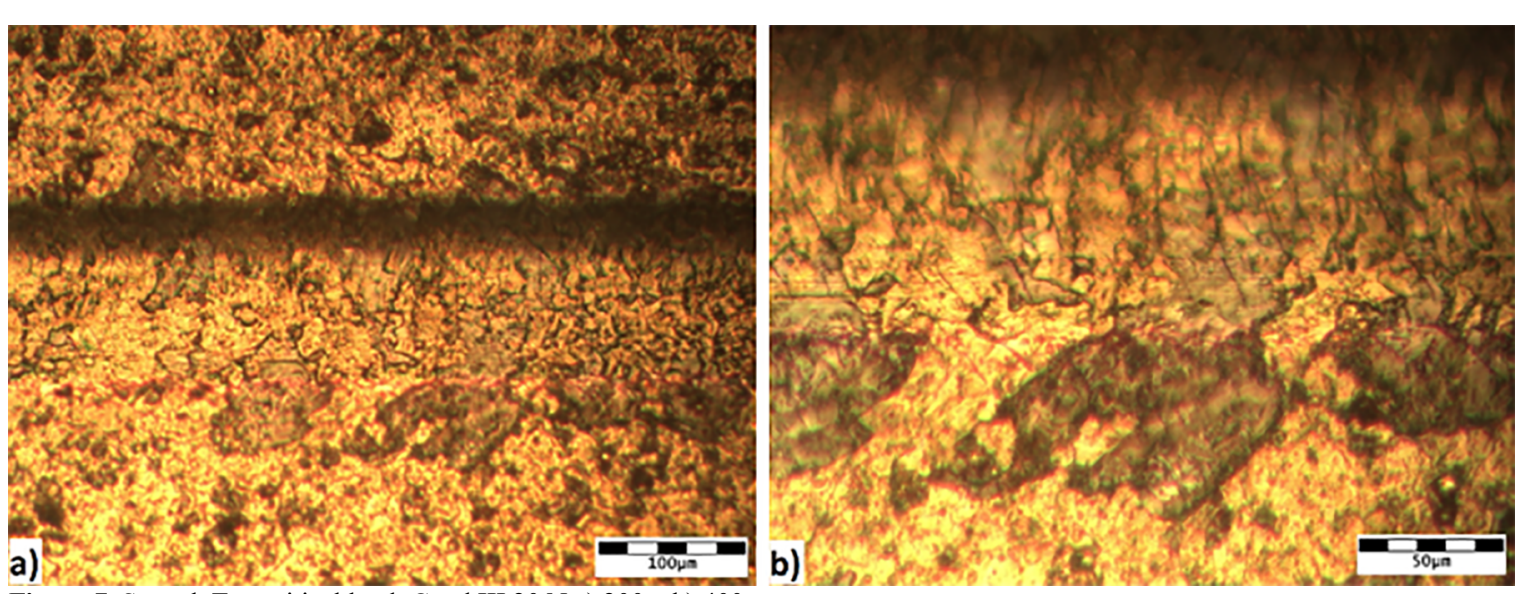

Figure 7. Scratch Test critical load: Cond III $20 \mathrm{~N}$ a) 200x, b) 400x

For the Condition I, $30 \%$ of the samples failed at a load lower than $10 \mathrm{~N}$, but the critical load for most of them was 20 N. Fig. 6a) presents one example with $20 \mathrm{~N}$ where buckling spallation damage is observed, according to the $\mathrm{C} 1624$ Standard. Meanwhile, all the samples of Condition II failed at $5 \mathrm{~N}$ (Fig. 6b)) showing large area interfacial spallation, which corresponds to an adhesive failure, indicating that the temperature has not benefit the adhesion of the film.

In order to know if the sputtering time was a relevant factor in relation to adhesion, it was increased from 60 minutes to 90,120 and 150 minutes. It could be concluded from the scratch test results that they were only slightly better than the previous condition (I). Fig. 7 presents a typical scratch track of $20 \mathrm{~N}$, with magnification $200 \mathrm{x}$ (Fig. 7a)) and 400x (Fig.7b)), for a sample of condition III. For this condition, the critical load augmented to a value between $20 \mathrm{~N}$ and $30 \mathrm{~N}$, but the surface percentage with the coating detached when the samples were removed from the PVD chamber did not change. Therefore, the adhesion improvement achieved with the increase in sputtering time was considered not good enough.

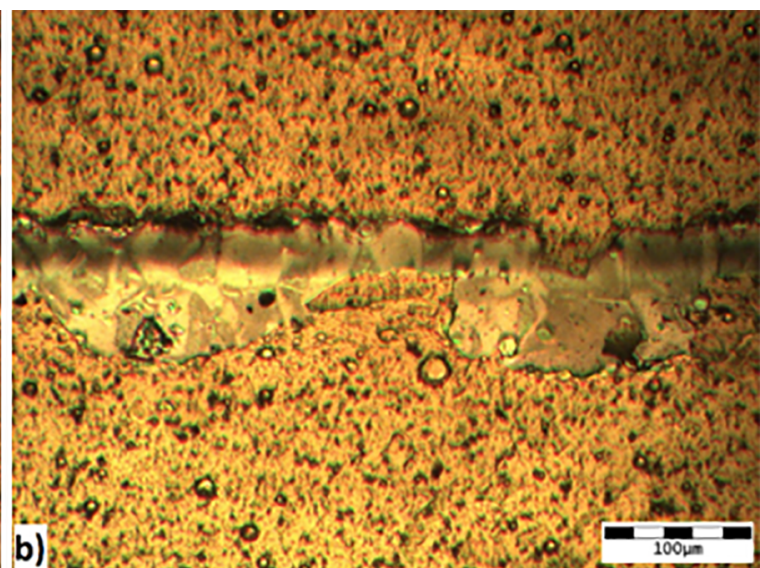

a) 
Following the scheme used for Conditions I and II, the gas mixing with the addition of $\mathrm{H}_{2}$ led to Conditions IV and $\mathrm{V}$. In this case, a big difference arises, because most of the samples showed a uniform coating over the surface when they were removed from the vacuum chamber. Fig. 8a) shows a representative image of the scratch track obtained for Condition IV, where in $70 \%$ of the samples, the critical load was lower than $5 \mathrm{~N}$, and the damage they presented could be classified as large area interfacial spallation, according to the C1624 Standard. On the other side, samples of Condition V with a critical load lower than $20 \mathrm{~N}$; represented half of the samples, and of the $50 \%$ remaining, $30 \%$ had $30 \mathrm{~N}$ critical load and $20 \%$ reached $40 \mathrm{~N}$ (Fig. 8 b)). Most of the samples of this condition showed forward "chevron" tensile cracks, without any delamination.

The scratch test results indicated that the adhesion has been improved with the addition of $\mathrm{H}_{2}$ in the gas mixing and the use of temperature, where the samples did not present adhesive failure in any test. The material accumulated outside the track reveals only mild cohesive failure, generally found in these tests.

The positive influence of $\mathrm{H}_{2}$ in a sputtering process had been observed before, being able to remove the stainless steel native oxide before plasma nitriding ${ }^{21}$. Others authors have used Ar$\mathrm{H}_{2}$ sputtering with the same purpose $\mathrm{e}^{4,5,10}$, because the removal of oxide layers and contaminants on the surface before plasma nitriding is essential to allow the nitrogen diffusion, especially in the case of stainless steels. After plasma nitriding of stainless steels, these oxide layers are built again and they could represent a problem in the film growing or in the adhesion properties. This case was studied by Barshilia et al., who carried out a pre-cleaning phase with $\mathrm{Ar}+\mathrm{H}_{2}$ plasma etching before PVD TiAlN coatings onto mild steel substrates using the magnetron sputtering technique at a temperature of $325^{\circ} \mathrm{C}^{16}$.

\subsection{Rockwell C Indentation}

Between four and five Rockwell $\mathrm{C}$ indentation tests were performed in each sample for each condition and the results are presented in column graphs, where the number of indentations for each level of cracking and coating delamination around the indentation according to the criterions of VDI 3198 Standard are shown. The indentations were performed in different regions of the surface.

For the Condition I, more than $60 \%$ and the totality of the samples of Condition II have qualified as "non acceptable" (HF5 and HF6). The column graphs for condition I and II are shown in Fig. 9a) and b) respectively. It can be also observed that the totality of acceptable samples of Condition I corresponded to HF4. This means that the Argon sputtering was not very effective to remove the oxide layer and contaminants, and the temperature increase, instead of improving the adhesion had a negative effect, the same result was observed in the Scratch Tests.
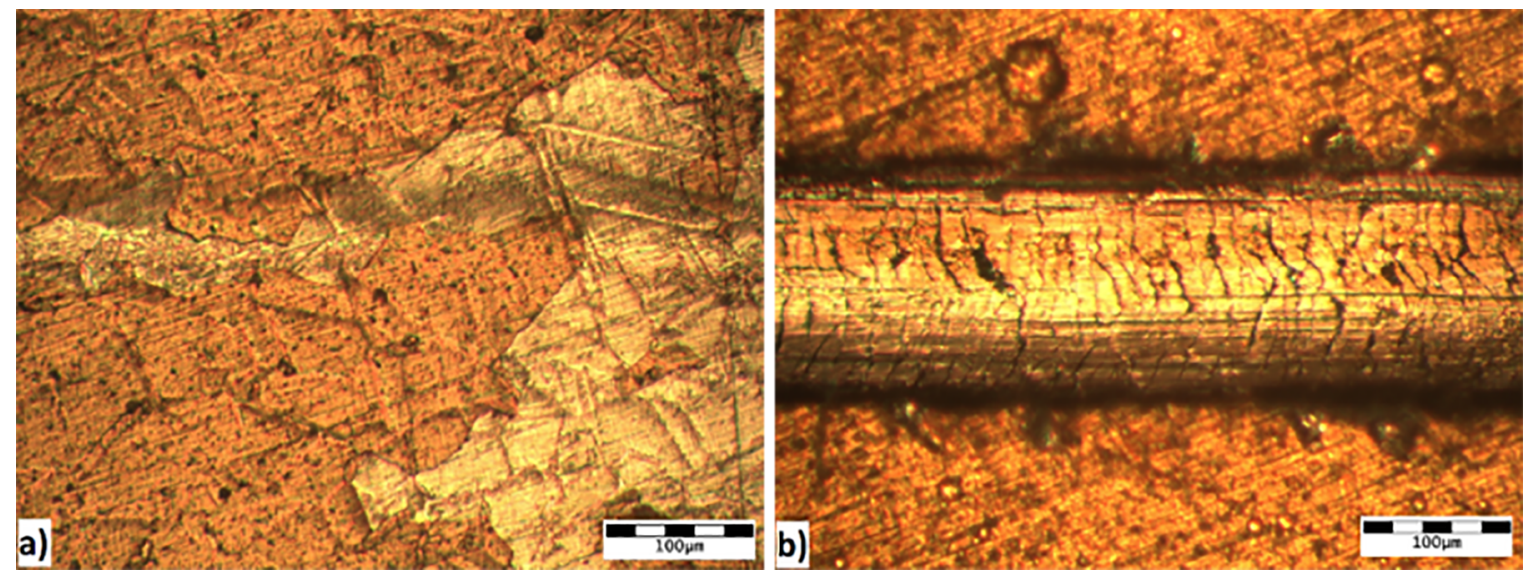

Figure 8. Scratch Test critical load: a) Cond. IV 5 N 200x, b) Cond V 40 N 200x.

a)

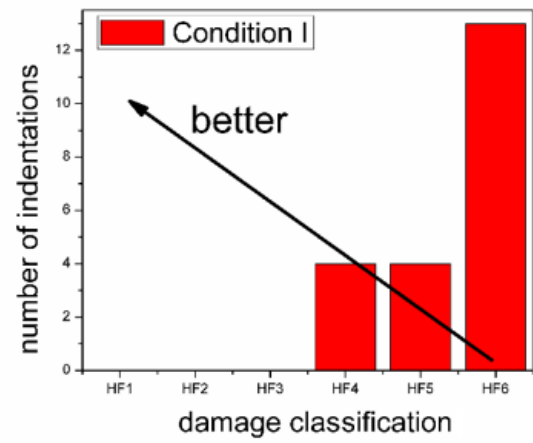

b)

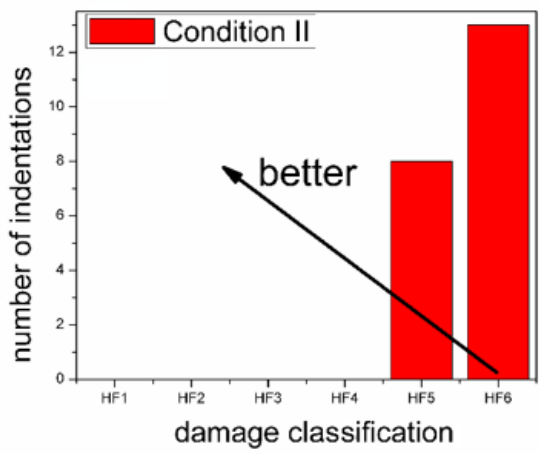

Figure 9. RC Indentation Graphics: a) Condition I, b) Condition II. 
The micrograph of Fig. 10a), corresponding to the Rockwell C test scar of one sample of Condition I, shows radial cracks and some delamination around and near the indentation scar, and it can be classified as HF5. In the case of Condition II, all the samples presented radial cracks and large delamination area around the indentation scar, as it is showed in Fig. 10b).

The slight improvement in adhesion revealed by the scratch tests and obtained due to the increasing sputtering time in Condition III, was also present in the indentations tests results, however with a bigger difference. In this case, $30 \%$ of the tests resulted acceptable, as it can be seen in the column graph of Fig. 11a), and in the micrograph of Fig. 11b), which corresponds to a sample classified as acceptable with HF4. In this sample, the radial cracks are not so remarkable, and it is possible to note that the vicinity of the scar presents small zones without coating, but not large delamination area was observed.

The $\mathrm{H}_{2}$ incorporation into the gas mixing in the sputtering process allowed obtaining samples with an improved adhesion behavior in the RC Indentation test whether the heater was turn off or on. For the Condition IV, the samples were maintained at room temperature during the cleaning process and $80 \%$ of the samples were delaminated around the indentation boundaries, corresponding to HF6, while at least $20 \%$ of them classified as acceptable. The graphic that summarizes the indentation test results is presented in Fig. 12a), and a typical micrograph with an imprint HF6 is shown in Fig. 13a) and Fig. 13b). In the scratch test, on the other hand, for Condition IV, all the samples delaminated with the minimum load. These differences in the performance between both tests could be due to the different mechanisms involved in the test.

Scratch and RC indentation tests produce different deformation and adhesion failure mechanisms, and for this reason, the results are not always the same after applying one or the other test. In both of them, normal forces are acting, but in the scratch test the mechanism is dynamic, adding shear forces in the direction of the indenter movement, and it is static in RC indentation. In the RC indentation test, the penetration of indenter induce plastic deformation of the substrate and film fracture. However, the combination of the contact geometry with the applied load favors shear stresses at the film-substrate interface ${ }^{33}$.

For the Condition V, both tests yielded the same results: when the $\mathrm{Ar}-\mathrm{H}_{2}$ sputtering was performed at $300^{\circ} \mathrm{C}$ temperature for 150 minutes, most of the samples did not only qualified as acceptable but also were classified with the highest level HF1 as it is showed in Fig. 12b), a result that was not obtained for the other conditions. A typical micrograph of an imprint for condition $\mathrm{V}$ is shown in Fig. 13c)
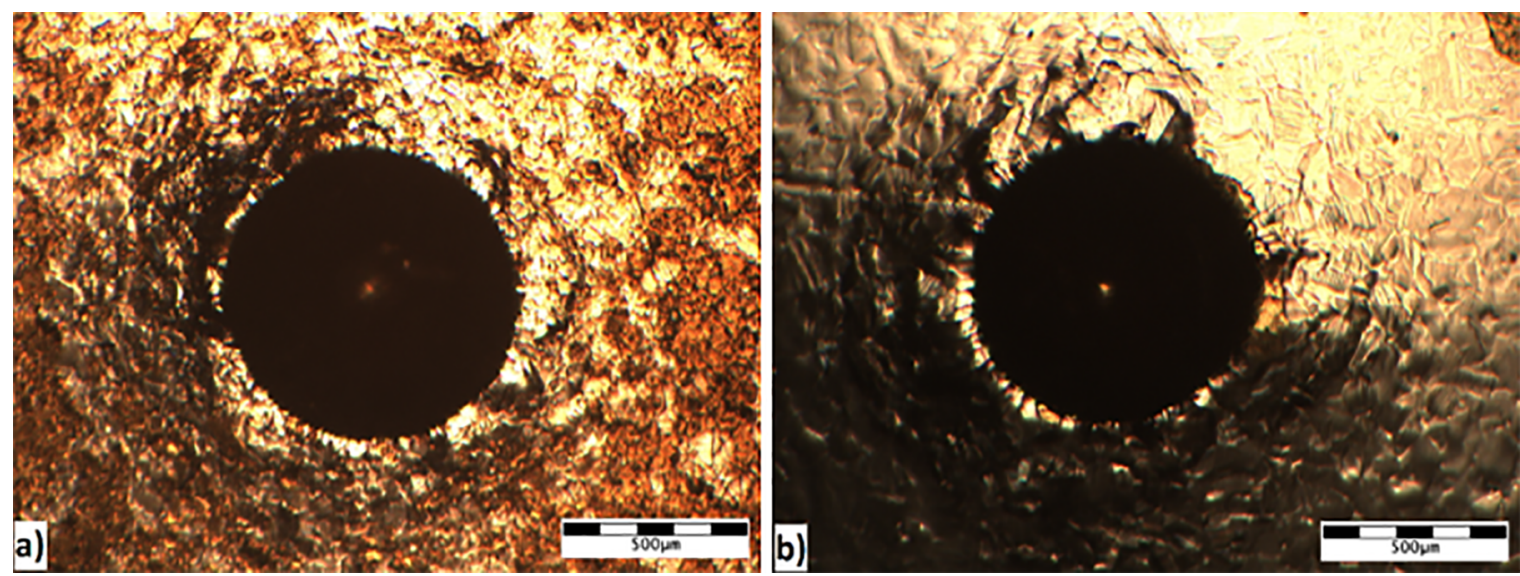

Figure 10. Rockwell C indentation micrograph 50x: a) Cond. I, b) Cond. II.

a)

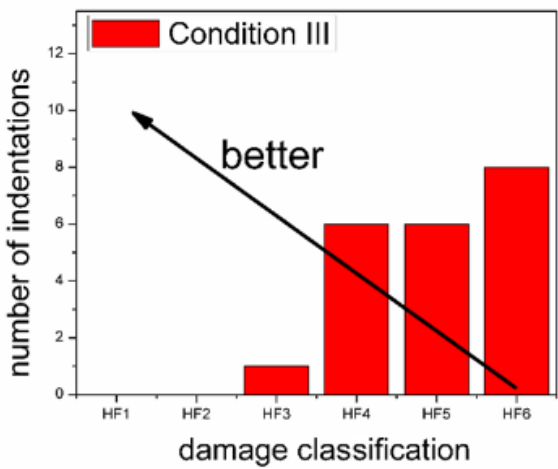

b)

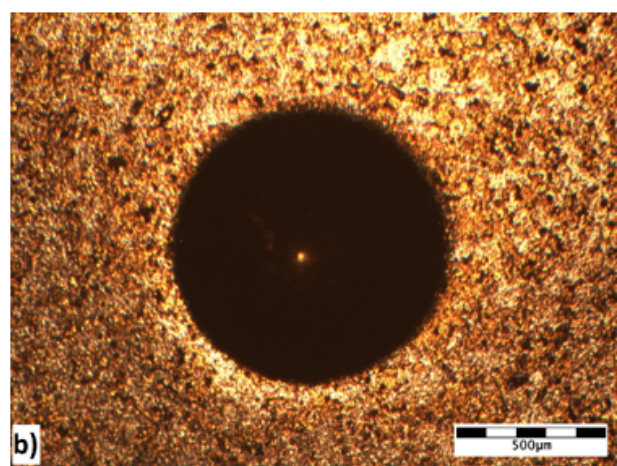

Figure 11. RC Indentation Condition III: a) Graphic, b) Micrograph 50x. 
a)

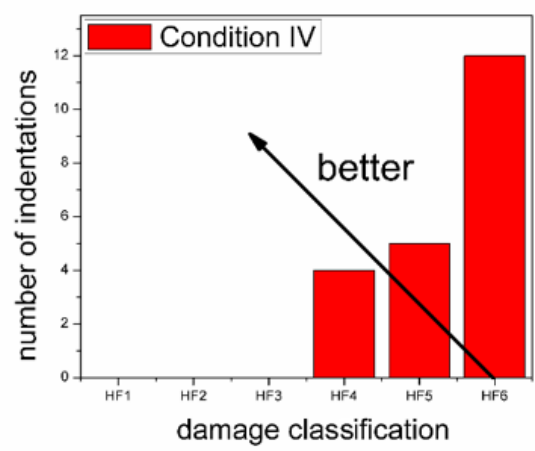

b)

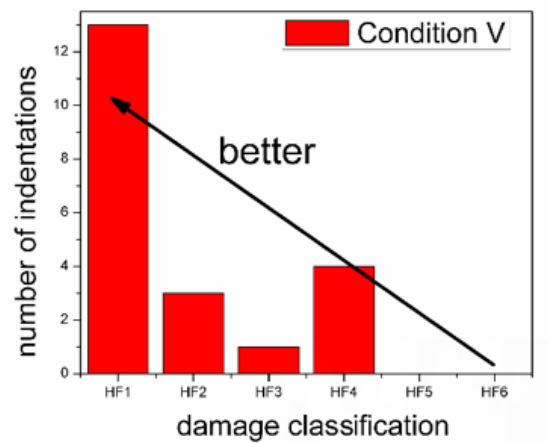

Figure 12. RC Indentation Graphics: a) Condition IV, b) Condition V.
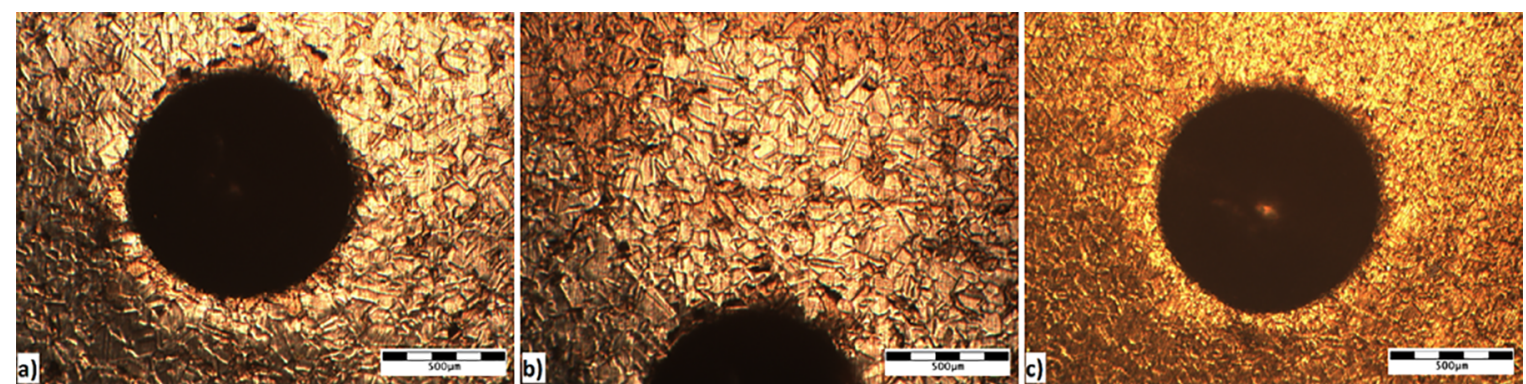

Figure 13. Rockwell C indentation micrographs 50x: a) and b) Cond. IV, c) Cond. V.

The results presented in this work, indicate that the sputtering parameters for the pre-cleaning step to prepare the surface for nitrogen diffusion in the stainless steel plasma nitriding process, are also suitable for the pre-treatment step before the PBII\&D coatings over already nitrided stainless steels.

It was found that the film adhesion onto stainless steel which was previously ion nitrided was remarkable improved when the pre-cleaning combined $\mathrm{H}_{2}-\mathrm{Ar}$ in the gas mixing sputtering and temperature were added in the whole process. Films with the same thickness $(2 \mu \mathrm{m})$, with the same Ti interlayer, and grown using the same process parameters, presented different adhesion behavior according to the pretreatment which was previously carried out. The Scratch Test and RC indentation results showed the best coating adhesion for samples of Condition $\mathrm{V}$, neither spallation at the edge of the scratch track nor delamination near the RC indentation scar were observed.

\section{Conclusions}

In this research, different pre-treatments were performed in order to study their influence on the adhesion of TiN films deposited by PBII\&D over nitrided austenitic stainless steel and the conclusions can be summarized as following:

The morphology and the film thickness were not affected by the pre-treatment conditions, only depending on the PBII\&D process parameters, but film adhesion was indeed affected.

The argon sputtering was not enough to ensure a good adhesion, presumably because it did not remove efficiently the oxide layer and contaminations developed on the stainless steel surface after the plasma nitriding treatment. Increasing time and temperature without changing the sputtering atmosphere was not enough to improve the adhesion either.

The incorporation of $\mathrm{H}_{2}$ in the sputtering gas mixing and the use of heating in the whole cleaning and deposition process up to $300^{\circ} \mathrm{C}$, yielded good adhesion results demonstrated in both tests, Scratch and RC Indentation.

\section{Acknowledgment}

The authors would like to thank the financial support of UTN PID Nr. 25D/065, of CONICET PIP 11220120100468, of University of Buenos Aires. PID 20020150100103BA and EU-LA Project SUMA2 to enable researches mobility.

\section{References}

1. Sendriks AJ. Corrosion of stainless steels. In: Orazem ME, Tribollet B. Electromechanical Impedance Spectroscopy. 2th ed. Hoboken, NJ, USA: John Wiley \& Sons, Inc.; 1996.

2. ASM Handbook. Surface Engineering. Vol. 5. United States of America: ASM Int.; 1994.

3. Manova D, Mändl S. Surface nitriding with energetic ions using plasma based ion implantation. In: Wei R, ed. Plasma Surface Engineering Research and its Practical Applications. Kerala: Research Signpost; 2008. p. 293-312.

4. Czerwiec T, Renevier N, Michel H. Low-temperature plasma-assisted nitrided. Surface and Coatings Technology. 2000;131(1-3):267-277. 
5. Gil L, Brühl S, Jiménez L, Leon O, Guevara R, Staia MH. Corrosion performance of the plasma nitrided 316L stainless steel. Surface and Coatings Technology. 2006;201(7):44244429 .

6. Sanders DM, Anders A. Review of cathodic arc deposition technology at the start of the new millennium. Surface and Coatings Technology. 2000;133-134:78-90.

7. Bilek MMM, McKenzie DR, Tarrant RN, Lim SHM, McCulloch DG. Plasma-based ion implantation utilising a cathodic arc plasma. Surface and Coatings Technology. 2002;156(1):136-142.

8. Mändl S, Manova D. Formation of hard coatings using plasma based ion implantation \& deposition. In: Wei R, ed. Plasma Surface Engineering Research and its Practical Applications. Kerala: Research Signpost; 2008. p. 273-292.

9. De Las Heras E, Egidi DA, Corengia P, González-Santamaría D, García-Luis A, Brizuela M, López GA, Flores M. Duplex surface treatment of an AISI 316L stainless steel; microstructure and tribological behavior. Surface and Coatings Technology. 2008;202(13):2945-2954.

10. Den Y, Tang C, Wang Y, Chen L, Cai P, Kuang T, Lei S, Zhou $\mathrm{K}$. Effects of tailored of the nitriding layers on comprehensive properties of duplex plasma-treated AlTiN coatings. Ceramics International. 2017;43(12):8721-8729.

11. Sprute T, Tillmann W, Grisales D, Selvadurai U, Fisher G. Influence of substrate pre-treatments on residual stresses and tribo-mechanical properties of TiAlN-based PVD coatings. Surface and Coatings Technology. 2014;260:369-379.

12. Bull SJ, Berasetegui EG. An overview of the potential of quantitative coating adhesion measurement by scratch testing. Tribology International. 2006;39:99-114.

13. Podgornik B, Vizintin J. Tribology of thin films and their use in the field of machine elements. Vacuum. 2003;68(1):39-47.

14. Gerth J, Wiklund U. The influence of metallic interlayers on the adhesion of PVD TiN coatings on high-speed steel. Wear. 2008;264(9):885-892.

15. Vega J, Scheerer H, Andersohn G, Oechsner M. Experimental studies of the effect of Ti interlayers on the corrosion resistance of TiN PVD coatings by using electrochemical methods. Corrosion Science. 2018;133:240-250.

16. Barshilia HC, Ananth A, Khan J, Srinivas G. Ar $+\mathrm{H}_{2}$ plasma etching for improved adhesion of PVD coatings on steel substrates. Vacuum. 2012;86(8):1165-1173.

17. Jones BJ, Anguilano L, Ojeda JJ. Argon plasma treatment techniques on steel and effects on diamond-like carbon structure and delamination. Diamond and Related Materials. 2011;20(7):1030-1035.

18. Borges CFM, Hennecke S, Pfender E. Decreasing chromium precipitation in AISI 304 stainless steel during the plasmanitriding process. Surface and Coatings Technology. 2000;123(2-3):112-121.
19. Bull SJ, Chalker PR, Ayres CF, Rickerby DS. The influence of titanium interlayers on the adhesion of titanium nitride coatings obtained by plasma-assisted chemical vapour deposition. Materials Science and Engineering: A. 1991;139:71-78.

20. Kim SK, Yoo JS, Priest JM, Fewell MP. Characteristics of martensitic stainless steel nitrided in a low-pressure RF plasma. Surface and Coatings Technology. 2003;163-164:380-385.

21. Tillmann W, Vogli E, Momeni S. Improvement of press dies used for the production of diamond composites by means of DUPLEX-PVD-coatings. Surface and Coatings Technology. 2010;205(5):1571-1577

22. Holmberg K, Matthewst A, Ronkainen H. Coatings tribology. Contact mechanisms and surface design. Tribology International. 1998;31(1-3):107-120

23. Lei S, Huang JH, Chen H. Measurement of residual stress on TiN/Ti bilayer thin films using average X-ray strain combined with laser curvature and nanoindentation methods. Materials Chemistry and Physics. 2017;199:185-192.

24. Vaca LS, Márquez A, Brühl SP. Structural and tribological properties of Ti-TiN coatings obtained with a vacuum arc. Journal of Physics Conference Series. 2012;370(1):012032.

25. De Las Heras E, Ybarra G, Lamas D, Cabo A, Dalibon EL, Brühl SP. Plasma nitriding of $316 \mathrm{~L}$ stainless steel in two different $\mathrm{N}_{2}-\mathrm{H}_{2}$ atmospheres - Influence on microstructure and corrosion resistance. Surface and Coatings Technology. 2017;313:47-54

26. ASTM C1624-05. Standard Test Method for Adhesion Strength and Mechanical Failure Modes of Ceramic Coatings by Quantitative Single Point Scratch Testing. West Conshohocken, PA: ASTM International; 2015.

27. Verein Deutscher Ingenieure Normen, VDI 3198, VDI-Verlag, Dusseldorf, 1991.

28. Nosei L, Avalos M, Gómez BJA, Naches JL, Feugeas J. Stability under temperature of expanded austenite developed on stainless steel AISI 316L by ion nitriding. Thin Solid Film. 2004;468(1-2):134-141

29. ICDD $\operatorname{card} \mathrm{N}^{\circ}: 00-038-1420$

30. ICDD card $\mathrm{N}^{\mathrm{o}}: 00-044-1294$

31. Bunshah RF, Hultmannm L, Sundgren J. Handbook of hard coating. Deposition Technologies, properties and applications. In: Hultmannm L, Sundgren J, eds. Structure/Property Relationships for hard Coatings. New York (USA): Noyes Publications; 2001. p. 211-223.

32. Oettel H, Wiedemann R. Residual stresses in PVD hard coatings. Surface and Coatings Technology. 1995;76-77(Pt 1):265-273.

33. Vidakis N, Antoniadis A, Bilalis N. The VDI 3198 indentation test evaluation of a reliable qualitative control for layered compounds. Journal of Materials Processing Technology. 2003;143-144(1):481-485. 